Ricardo Puziol de Oliveira*, Jorge Alberto Achcar and Altacílio Aparecido Nunes

\title{
Modeling the incidence and death rates of COVID-19 pandemic in different regions of the world
}

https://doi.org/10.1515/em-2020-0017

Received June 19, 2020; accepted August 4, 2020; published online August 28, 2020

\begin{abstract}
This paper reports a broad study using epidemic-related counting data of COVID-19 disease caused by the novel coronavirus (SARS-CoV-2). The considered dataset refers to 119 countries' daily counts of reported cases and deaths in a fixed period. For the data analysis, it has been adopted a beta regression model assuming different regions of the world where it was possible to discover important economic, health and social factors affecting the behavior of the pandemic in different countries. The Bayesian method was applied to fit the proposed model. Some interesting conclusions were obtained in this study, which could be of great interest to epidemiologists, health authorities, and the general public in the face of the forthcoming hard times of the global pandemic.
\end{abstract}

Keywords: Bayesian methods; beta regression models; cases and deaths rates; COVID-19 counting data; SARS-CoV-2.

\section{Introduction}

An epidemic could be defined as the community occurrence of a group of illnesses of similar nature derived from a common or a propagated source (Gordis 2014), on the other hand, when an epidemic grows on a worldwide scale, then it is called a pandemic. In human history, epidemic diseases have killed millions of people at different times in varying speeds. Viruses have caused some of the worst registered epidemics, as smallpox (1896 to 1980), Spanish flu (1918 to 1919), measles (until 1963), AIDS (since 1981) and dengue over the last thirty years (World Health Organization 2020b). In 2009, cases of Influenza A (H1N1) were registered worldwide, and an outbreak of Ebola occurred between 2013 and 2016 in West Africa (see World Health Organization 2016). Over the last few years, the major epidemic diseases in Brazil were caused by Chikungunya (in 2013) and Zika (in 2015) viruses. These diseases had produced a vast international commotion as the number of new positive cases grew up considerably precisely when the country was about to host two of the most prominent sports events worldwide: 2014 FIFA World Cup and 2016 Summer Olympics Games.

Despite all the battles won against previous epidemics and pandemics, the world is currently experiencing one of the most significant challenges of the twenty-first century, the pandemic caused by the novel coronavirus. The COVID-19 disease is a viral infection of disruptive nature that is spreading quickly around the world since January 2020. The virus has emerged late in 2019 in the city of Wuhan, Hubei Province of China. According to the Situation Report 80 from the World Health Organization (WHO), the number of global cases reached 8,043,487 people until June 16, 2020, among which 439,487 died with COVID-19. Since December 2019, the pandemic of COVID-19 has spread to new areas and has increased considerably in the already affected areas. In the Situation Report 1 (January 21, 2020), there were only 282 confirmed cases in the region covering China, Japan, the Republic of Korea, and Thailand. However, in Situation Report 77 (April 06, 2020), there were

*Corresponding author: Ricardo Puziol de Oliveira, Universidade Estadual de Maringá, Av. Ângelo Moreira da Fonseca, 1800 Parque Danielle, Umuarama, 87506-370, Brazil, E-mail: rpuziol.oliveira@gmail.com Jorge Alberto Achcar and Altacílio Aparecido Nunes, Universidade de São Paulo Faculdade de Medicina de Ribeirão Preto, Ribeirao Preto, São Paulo, Brazil. https://orcid.org/0000-0001-9934-920X (A.A. Nunes) 
1,210,956 confirmed cases and 67,594 deaths worldwide, being the South Sudan the last country to register cases of COVID-19. The disease initially called COVID-19 (Coronavirus Disease 2019) started to have the causative virus classified as SARS-CoV-2 by the International Virus Taxonomy Committee (Y. Chen et al. 2020). To track the virus, the WHO has updated the Laboratory Testing Strategy at March 21, 2020 (Lan et al. 2020) according to the different transmission scenarios: countries with no cases; countries with one or more cases (sporadic cases); countries experiencing a series of cases related to geographic location or common exposure (a group of cases); and countries experiencing massive outbreaks or sustained and pervasive local transmission (community transmission).

COVID-19 is a respiratory disease that affects different people in different ways, so that most people infected with the new coronavirus will experience mild to moderate respiratory illness, recovering without requiring specific treatments (World Health Organization 2020a). According to the WHO, the primary symptoms of COVID-19 are fever, tiredness, dry cough, shortness of breath, and sore throat, and very few people will report diarrhea, nausea, or runny nose. Older people and those with underlying medical conditions like cardiovascular disease, diabetes, chronic respiratory disease, and cancer are more likely to develop severe illness and death. The virus spreads primarily through droplets of saliva or discharge from the nose when an infected person coughs or sneezes. There are vaccines being developed and some are in the testing phase. There is no specific treatment for the disease and patients are treated according the symptoms they present, however, several ongoing clinical trials are being conducted to find potential treatments and drug repurposing opportunities. There are several vaccines under development, some already in phase III and others in the initial testing phase. Many researchers are putting great effort into the last months to better understand the behavior of the new coronavirus. It can be seen in the hundreds of scientific works being released in a short time (J.F.-W Chan 2020, K.-H. Chan 2020; Chen 2020; D. Chen et al. 2020; N. Chen et al. 2020; da Silva et al. 2020; Han et al. 2020; Huang et al. 2020; Kandel et al. 2020; Lai et al. 2020; Li et al. 2020; Lu et al. 2020; Lupia et al. 2020; Pung et al. 2020; Ribeiro et al. 2020; Shereen et al. 2020; Sohrabi et al. 2020; A. Wu et al. 2020; J. T. Wu et al. 2020; Zhao et al. 2020).

It is observed in the literature that countries in different regions could have different morbidity and mortality indicators such as Incidence Rate/100,000 (IR), Mortality Rate by cause/100,000 (MRC) and CaseFatality Rate/100 (CFR), depending on the heath structure, such as primary care units, specialized outpatient clinics and hospitals with and without intensive care units (ICU), as well as, number of diagnostic tests to detect coronavirus for the population, policy implemented in each country to isolate the population, that is, quarantine or total isolation and possibly other factors as ethical groups or climate differences that could affect the incidence and death rates. An important factor that affects the IR, MRC and CFR are underdiagnoses and/or under-notification, especially in the poorest countries of the world where there is great lack of hospitals, medical equipment and diagnostic tests to detect COVID-19, leading to very low and misleading rates related to the epidemic.

Thus, given the above, this article aims to analyze the correlations/associations between IR, MRC and CFR by COVID-19 with some variables described below, so in this study, 119 countries from different regions of the world were considered to compare such rates. The covariates assumed in this study for each country are:

(1) General information: population $/ \mathrm{km}^{2}$.

(2) Economy: GDP in million of current US\$ and GDP per capita in current US\$.

(3) Social indicators: urban population (\% of total population); infant mortality rate (deaths by 1,000 live births); physicians (number by 1,000 inhabitants) a health indicator and current expenditure in health (\% of GDP on health spending) another health indicator.

This paper is organized as follows: Section 2 presents an overall description of the considered dataset and the proposed regression model for comparison of IR, MRC and CFR by COVID-19, notified from each country. The obtained results and the pertinent discussions are presented in Section 3. General comments and concluding remarks are addressed in Section 4. 


\section{Material and methods}

\section{Dataset}

The data set consisted of the daily counting of new cases and daily deaths since until May 04, 2020 reported in the site European Union (EU) open data portal (https://data.europa.eu/euodp/en/data/dataset/covid-19-coronavirus-data). Moreover, some covariates associated to each country obtained from United Nations site (https://data.un.org/) relative for the year 2019, are considered in the data analysis assuming beta regression models under a Bayesian approach with responses given by IR, MRC and CFR to verify if there are significant effects of these covariates in the responses. The EU collects and manages data related to the COVID-19 pandemic involving daily counting of new cases and daily deaths. The SARS-CoV-2 has already infected the population since the beginning of the year 2020, especially in the northern hemisphere but in other countries, the infection only started in more recent months such as the southern hemisphere, leading a great heterogeneity of the data. For a better understanding of this behavior, the 119 countries considered in the study were selected from the world classified in 11 regions: East Asia, Central Asia, Asia Middle East, Europe, North America, Central America, South America, Oceania, Caribbean, North Africa and Sub Saharan Africa.

\section{Beta regression model for the COVID-19 rates}

Statistical modeling of daily and accumulated disease counting data can be considered under different approaches. Under a probabilistic point of view, the epidemic curves related to disease counting data could be modeled as a stochastic process (in the form of a counting process). Alternatively, one may consider the use of classical nonlinear models as those widely used to describe phenomena as population growth in ecology and demography or the individual body height or biomass (for growth analysis of subjects in physiology). Standard inference methods to obtain point and interval estimates for the parameters of growth models are well discussed within the nonlinear modeling literature (Bates and Watts 1980, 1988; Hazewinkel 2001; Ratkowsky 1983; Seber and Wild 2003).

Our approach in this paper is based on three univariate beta regression models for the responses $Y_{1}=\mathrm{IR}, Y_{2}=\mathrm{MRC}$ and $Y_{3}=\mathrm{CFR}$ in presence of the following covariates: population $/ \mathrm{km}^{2}$, GDP (Gross Domestic Product of the country) in million of current US\$ in logarithmic scale, GDP per capita in current US\$ in logarithmic scale, urban population (\% of total population), infant mortality rate (deaths by 1,000 live births), number of physicians by 1,000 inhabitants and \% of GDP on health spending of each country in the study. In the regression model it is also considered categorical variables related to the 11 regions (use of dummy variables for categorical covariates regions where East Asia is considered as reference). Thus, since $Y_{1}, Y_{2}$ and $Y_{3}$ are defined in the interval [0, 1], it is assumed beta probability distributions for each random variable, given by the density probability function,

$$
f(y \mid \alpha, \beta)=B(\alpha, \beta) y^{\alpha-1}(1-y)^{\beta-1}, 0<y<1,
$$

where $B(\alpha, \beta)$ is a beta function defined by $B(\alpha, \beta)=\Gamma(\alpha+\beta) / \Gamma(\alpha) \Gamma(\beta)$ where $\Gamma(\kappa)=\int_{0}^{\infty} x^{\kappa-1} e^{-x} d x$. The Beta distribution is denoted by $Y \sim \operatorname{Beta}(\alpha, \beta)$. The mean and variance of the beta distribution are given respectively by $\mu=\alpha /(\alpha+\beta)$ and $\sigma^{2}=\alpha \beta /\left[(\alpha+\beta)^{2}(\alpha+\beta+1)\right]$.

In presence of a vector of covariates associated to each unit, it is assumed a regression model considering a re-parametrized form for the beta distribution with density (1) given by, $\mu=\alpha /(\alpha+\beta)$ and $\Phi=\alpha+\beta$ (Ferrari and Cribari-Neto 2004; Jørgensen 1997). That is, $\alpha=\Phi \mu, \beta=(1-\mu) \Phi$ with $E(Y)=\mu$ and $\operatorname{var}(Y)=V(\mu) /(1+\Phi)$ where $V(\mu)=\mu(1-\mu)$, so that $\mu$ is the mean of the response variable and $\Phi$ can be interpreted as a precision parameter in the sense that, for fixed $\mu$, the larger the value of $\Phi$, the smaller the variance of $Y$. The density of the random variable $Y$ can be written, in the new parameterization, as,

$$
f(y \mid \mu, \Phi)=\frac{\Gamma(\Phi)}{\Gamma(\Phi \mu) \Gamma(\Phi(1-\mu))} y^{\Phi \mu-1}(1-y)^{\Phi(1-\mu)-1}, 0<\mu<1 \quad \text { and } \Phi>0 .
$$

Assuming the presence of a covariate vector $\mathbf{x}=\left(x_{1}, x_{2}, \ldots, x_{p}\right)^{\mathrm{T}}$ with $p$ covariates associated to each COVID-19 rate, let us assume the following regression models (Cepeda-Cuervo et al. 2014),

$$
\operatorname{logit}(\mu)=\boldsymbol{\beta}^{\mathrm{T}} \boldsymbol{x} \text { and } \log (\Phi)=\boldsymbol{\alpha}^{\mathrm{T}} \boldsymbol{x}
$$

where $\boldsymbol{\alpha}=\left(\alpha_{1}, \ldots, \alpha_{p}\right)^{\mathrm{T}}$ and $\boldsymbol{\beta}=\left(\beta_{1}, \ldots, \beta_{p}\right)^{\mathrm{T}}$ are vectors of regression parameters. To construct our regression model, we assumed besides the economic, social and health covariates (population $/ \mathrm{km}^{2}$, GDP in million of current US\$ in logarithmic scale, GDP per capita in current US\$ in logarithmic scale, urban population ( $\%$ of total population), infant mortality rate (deaths by 1,000 live births), number of physicians by 1,000 inhabitants and \% of GDP on health spending of each country in the study) some dummy variables related to the unordered categorical variables regions of the world (Asia Middle East; Central America; Central Asia; Caribbean; East Asia; Europe; North Africa; North America; Oceania; South America and Sub Saharan Africa). Asia East region is assumed as reference. In this way, the regression models are given by, $\operatorname{logit}\left(\mu_{r i}\right)=g_{1}\left(\boldsymbol{\beta}_{r i}, x_{i}\right)$ and $\log \left(\Phi_{r i}\right)=g_{2}\left(\boldsymbol{\alpha}_{r i}, x_{i}\right)$ where, 


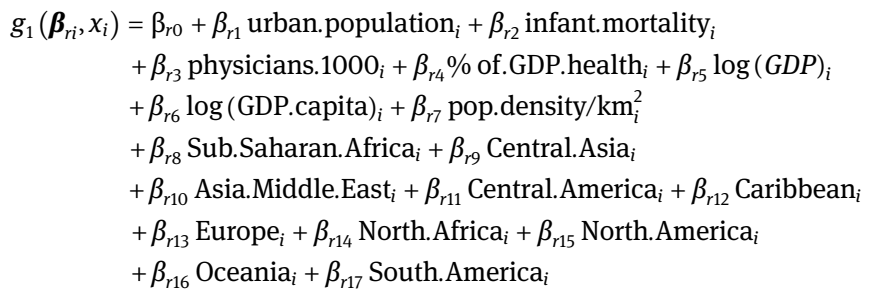

and,

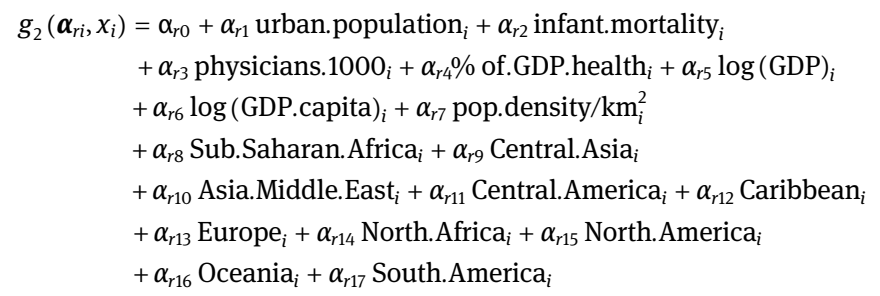

where $r=1$ (IR), $r=2$ (MRC) and $r=3$ (CFR) for $i=1, \ldots, 119$ (number of countries).

The beta regression approach based on (2) and (3) was proposed by Cepeda and Gamerman (2005) considering the joint modeling of the mean and variance or dispersion parameters in the bi-parametric exponential family, including joint modeling of the mean and dispersion parameters in the beta distribution, under a Bayesian approach. In our approach for COVID-19 rates, we present an analysis combining the joint prior distribution for the parameters of the model $\boldsymbol{\alpha}=\left(\alpha_{1}, \ldots, \alpha_{p}\right)^{\mathrm{T}}$ and $\boldsymbol{\beta}=\left(\beta_{1}, \ldots, \beta_{p}\right)^{\mathrm{T}}$ with the likelihood function based on the re-parametrized form of the beta density given by (2). The joint posterior distribution for all parameters is determined from the Bayes formula (Box and Tiao 2011) and the posterior summaries of interest are obtained using Markov Chain Monte Carlo (MCMC) methods (Chib and Greenberg 1995; Gelfand and Smith 1990).

\section{Results and discussion}

Figures 1, 2 and 3 show the box-plots of the rates (IR, MRC, CFR) where it is possible to see that countries in Europe and North America present larger IR and MRC when compared to countries of other regions of the world although these two regions present very high variability as compared to the other regions. It is important to point out that countries of these two regions have better health structures for the diagnostic of the infection, this is in line with the well-known and the close relationship between a higher case-fatality and mortality rate by COVID-19 and the worst structural health determinants (Bello-Chavolla et al. 2020). Also, it is observed that the MRC are very small for some regions of the world as East Asia, Oceania, North Africa and Sub Saharan Africa regions. It is important to highlight that countries in Oceania, such as Australia and New Zealand, managed to control the COVID-19 indicators with lower IR, MRC and CFR early, keeping the numbers constantly below those in other regions of the world (Cousins 2020; COVID-19 National Incident Room Surveillance Team and others 2020). However, the reasons for this better control are not fully clarified, while some authors point out climatic and geographical aspects (Chennakesavulu and Reddy, 2020), others highlight the role of demographic density (Ilardi et al. 2020; Rocklöv and Sjödin 2020) and some point to the cultural and socioeconomic characteristics, as well as political strategies employed in this region (Schulz et al. 2020; Varghese and $\mathrm{Xu} 2020$ ).

On the other hand, it is important to point out that for the Sub Saharan region the epidemic is starting in the time of this study (data set until May 04, 2020), thus, it is expected that the infection/disease by COVID-19 in the countries of this region, can show its dynamics, which for some authors tends to be of lesser impact, for several reasons such as lower population mobility, for example. However, for many other authors, the epidemic has the potential to have a major impact on these populations, considering poverty, the greater agglomeration, as well as the poor conditions of health services (Lumu 2020; Ongole et al. 2020; Osseni 2020). Countries in North America region presents the larger MRC, perhaps partly explained by the high population density and differences in age and racial structures of countries in that region with the greatest weight in Mexico and United 


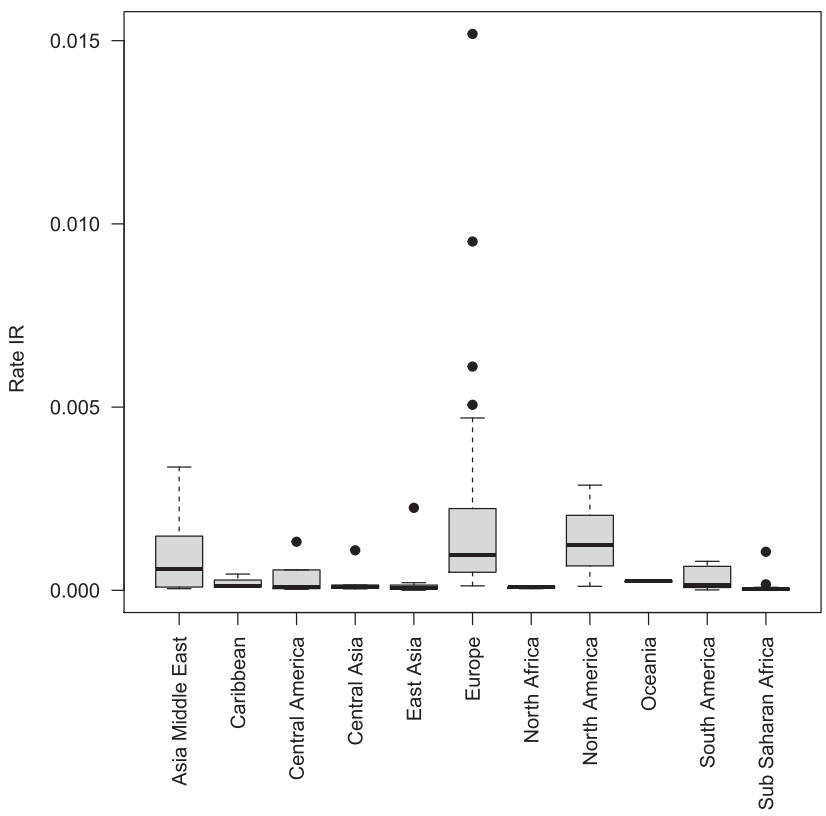

Figure 1: Box-plots for the IR in different regions of the world (the numbers are based on the cumulative number of cases and deaths).

States (Holmes et al. 2020; Mendez-Dominguez et al. 2020) while the CFR show more variability among the 11 regions with larger values for the countries in North Africa region, certainly largely due to poor health service structures in the countries of that region, with little capacity to deal with good response to critically ill patients, due to the lack of ICU beds and trained medical personnel (Ohia et al., 2020).

Table 1 presents summary statistics (means, standard-deviations, minimum and maximum for the IR, MRC and CFR for each region (Asia Middle East; Central America; Central Asia; Caribbean; East Asia; Europe; North Africa; North America; Oceania; South America; Sub Saharan Africa). Figures 4, 5 and 6 show the plots of the rate means against each region, from where it is observed large IR for three regions: Asia Middle East, Europe and North America, explained in part by being regions with high demographic density, highly dynamic populations in terms of mobilization and with an age structure that favors greater contagion and transmissibility (Ilardi et al., 2020; Rocklöv and Sjödin, 2020), in addition, these regions have invested in mass testing for the diagnosis of disease infection/disease, and thus, there is a greater detection of cases, and consequently greater IR (Edson et al. 2020; Sunjaya and Sunjaya 2020).

Also, it is observed large means for CFR for six regions: Central America; Caribbean; Europe; North Africa; North America and South America, which is possibly attributed to the fragility of the health system in countries in some regions, as well as the presence of older populations, known to be at higher risk of death from SARS-CoV-2 (Miles et al., 2020). On the other hand, small means of CFR are observed for the regions Asia Middle East; Central Asia; East Asia; Oceania and Sub Saharan Africa.

\section{Response: $Y_{1}(\mathrm{IR})$}

Using data from daily reported cases and deaths caused by COVID-19 in 119 countries until May 04, 2020, we have fitted the beta regression model assuming normal prior distributions Normal $N(0,1)$ for the parameters $\beta_{j}$ and Normal $N(0.0 .01)$ priors for the parameters $\alpha_{j}, j=0,1,2, \ldots, 17$. The choice of these priors was considered to have approximately non-informative priors and good performance of the MCMC simulation algorithm (for the regression parameters $\alpha_{j}$ good convergence was obtained for a normal prior distribution with small variances). Some sensitivity analysis considering different hyperparameters was also considered leading very similar results. The statistical analysis was carried out in the R software (R Core Team 2019). The R2OpenBUGS and the coda packages were used to obtain and monitor the Bayesian estimates and the convergence of the MCMC 

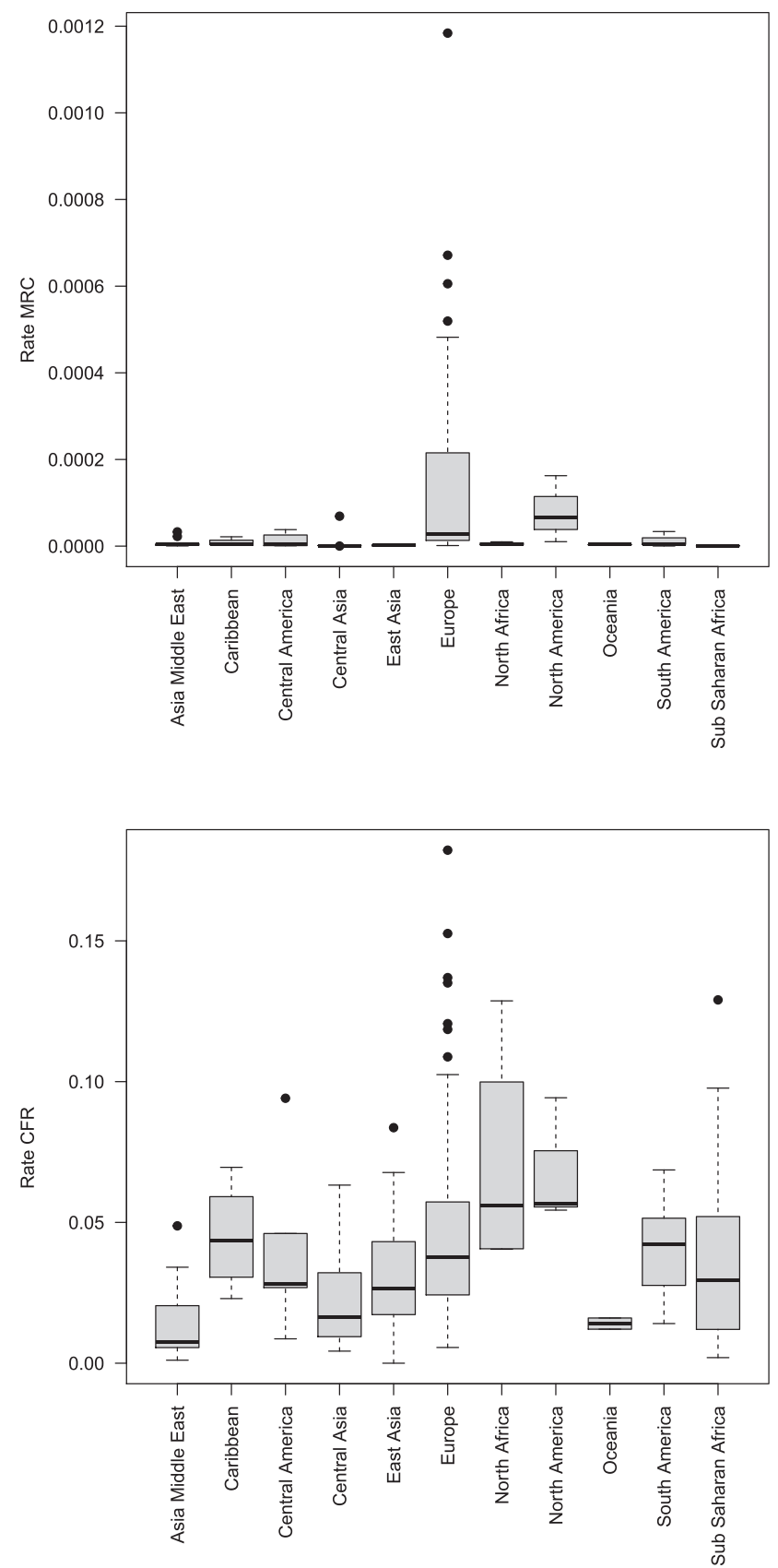

Figure 2: Box-plots for the MRC in different regions of the world (the numbers are based on the cumulative number of cases and deaths).

Figure 3: Box-plots for the CFR in different regions of the world (the numbers are based on the cumulative number of cases and deaths).

algorithm by usual time series plots for the simulated samples and Gelman and Rubin's methods (Brooks and Gelman 1998). Table 2 shows the posterior means (use of squared error loss function) for the regression parameters associated to each covariate, the posterior standard deviations (Std. Dev.) and 95\% credible intervals for all parameters from where it is observed that the following covariates show significant effects ( $95 \%$ credible intervals do not contain the zero value for the respective regression parameters) associated to the proposed regression model on the mean $\mu$ and on the parameter $\Phi$ (related to the precision) assuming the response IR:

- Urban population (for both regression models on $\mu$ and on $\Phi$, that is, parameters $\beta_{1}$ and $\alpha_{1}$ ).

- Infant mortality rate (for both regression models on $\mu$ and on $\Phi$, that is, parameters $\beta_{2}$ and $\alpha_{2}$ ).

- $\log$ (GDP-US $\$$ per capita) (for both regression models on $\mu$ and on $\Phi$, that is, parameters $\beta_{6}$ and $\alpha_{6}$ ). 
Table 1: Means, standard-deviations (Std. Dev.), number of countries $(N)$, minimum and maximum for the IR, MRC and CFR for each region (the numbers are based on the cumulative number of cases and deaths).

\begin{tabular}{|c|c|c|c|c|c|c|}
\hline Rates & Regions & $N$ & Mean & Std. Dev. & Minimum & Maximum \\
\hline \multirow[t]{11}{*}{ IR } & Asia Middle East & 12 & 128.6 & 154.6 & 4.6 & 559.1 \\
\hline & Central America & 6 & 47.6 & 66.5 & 4.1 & 172.3 \\
\hline & Central Asia & 6 & 29.5 & 44.2 & 6.5 & 119.1 \\
\hline & Caribbean & 4 & 23.9 & 22.1 & 8.3 & 56.6 \\
\hline & East Asia & 11 & 37.1 & 95 & 0.3 & 322.9 \\
\hline & Europe & 42 & 221.6 & 308.2 & 15.8 & $1,722.7$ \\
\hline & North Africa & 4 & 9.88 & 2.98 & 6.57 & 13.61 \\
\hline & North America & 3 & 177.7 & 168.3 & 18.6 & 354 \\
\hline & Oceania & 2 & 25.24 & 2.79 & 23.27 & 27.21 \\
\hline & South America & 10 & 53.6 & 63.3 & 1.2 & 172.9 \\
\hline & Sub Saharan Africa & 19 & 11.47 & 26.1 & 0.12 & 115.96 \\
\hline \multirow[t]{11}{*}{ MRC } & Asia Middle East & 12 & 0.958 & 1.221 & 0.088 & 4.127 \\
\hline & Central America & 6 & 1.53 & 1.974 & 0.099 & 4.788 \\
\hline & Central Asia & 6 & 1.39 & 3.03 & 0.03 & 7.58 \\
\hline & Caribbean & 4 & 1.127 & 1.279 & 0.307 & 3.036 \\
\hline & East Asia & 11 & 0.2773 & 0.1818 & 0 & 0.5691 \\
\hline & Europe & 42 & 15.16 & 24.65 & 0.13 & 121.36 \\
\hline & North Africa & 4 & 0.595 & 0.338 & 0.363 & 1.096 \\
\hline & North America & 3 & 10.78 & 9.52 & 1.71 & 20.69 \\
\hline & Oceania & 2 & 0.3947 & 0.0207 & 0.3801 & 0.4094 \\
\hline & South America & 10 & 2.049 & 2.841 & 0.035 & 9.155 \\
\hline & Sub Saharan Africa & 19 & 0.0976 & 0.0801 & 0.0027 & 0.2359 \\
\hline \multirow[t]{11}{*}{ CFR } & Asia Middle East & 12 & 1465 & 1,329 & 77 & 4225 \\
\hline & Central America & 6 & 3,355 & 2,421 & 812 & 7,773 \\
\hline & Central Asia & 6 & 2,358 & 2,210 & 465 & 6,367 \\
\hline & Caribbean & 4 & 4,561 & 2,108 & 1,919 & 6,897 \\
\hline & East Asia & 11 & 3,096 & 2,496 & 0 & 7,550 \\
\hline & Europe & 42 & 5,567 & 4,537 & 556 & 18,962 \\
\hline & North Africa & 4 & 6,170 & 3,090 & 3,549 & 10,349 \\
\hline & North America & 3 & 7,071 & 1,832 & 5,845 & 9,177 \\
\hline & Oceania & 2 & 1,578 & 256 & 1,397 & 1,759 \\
\hline & South America & 10 & 3,864 & 1,715 & 1,322 & 6,945 \\
\hline & Sub Saharan Africa & 19 & 3,287 & 2,904 & 180 & 11,765 \\
\hline
\end{tabular}

- $\log (\mathrm{GDP})$ (for both regression models on $\mu$ and on $\Phi$, that is, parameters $\beta_{5}$ and $\alpha_{5}$ ).

- $\%$ GDP spent in health (for both regression models on $\mu$ and on $\Phi$, that is, parameters $\beta_{4}$ and $\alpha_{4}$ ).

- Population density by $\mathrm{km}^{2}$ (for both regression models on $\mu$ and on $\Phi$, that is, parameters $\beta_{7}$ and $\alpha_{7}$ ).

It is observed that two of the covariates are linked to the economical situation of each country (log(GDP-US\$ per capita) and $\log (\mathrm{GDP})$ ); two covariates are linked to social situation of these countries (urban population and population density by $\mathrm{km}^{2}$ ) and two covariates are linked to health structure and its consequences (positive or negative) of each country (Infant mortality rate and \%GDP spent on health).

From the Monte Carlo estimates based on the simulated Gibbs samples for the posterior means (Table 2) of the regression parameters on $\mu$, we observe that: $\beta_{1}$ (urban population), $\beta_{2}$ (infant mortality rate), $\beta_{4}$ (\%GDP on health), $\beta_{6}\left(\log (\mathrm{GDP})\right.$ per capita) are negative; while $\beta_{5}(\log (\mathrm{GDP})), \beta_{7}$ (population density by $\mathrm{km}^{2}$ ) are positive. That is, the mean $\mu$ for the IR increases when the values of the covariates $\log (\mathrm{GDP})$ and population density by $\mathrm{km}^{2}$ increase. Possibly countries with larger GDP improves the diagnostic of the COVID-19 infection as showed by Lau et al. (2020). Countries with large population density by $\mathrm{km}^{2}$ also increases the mean of the IR by COVID19 as showed by Ilardi et al. (2020). 

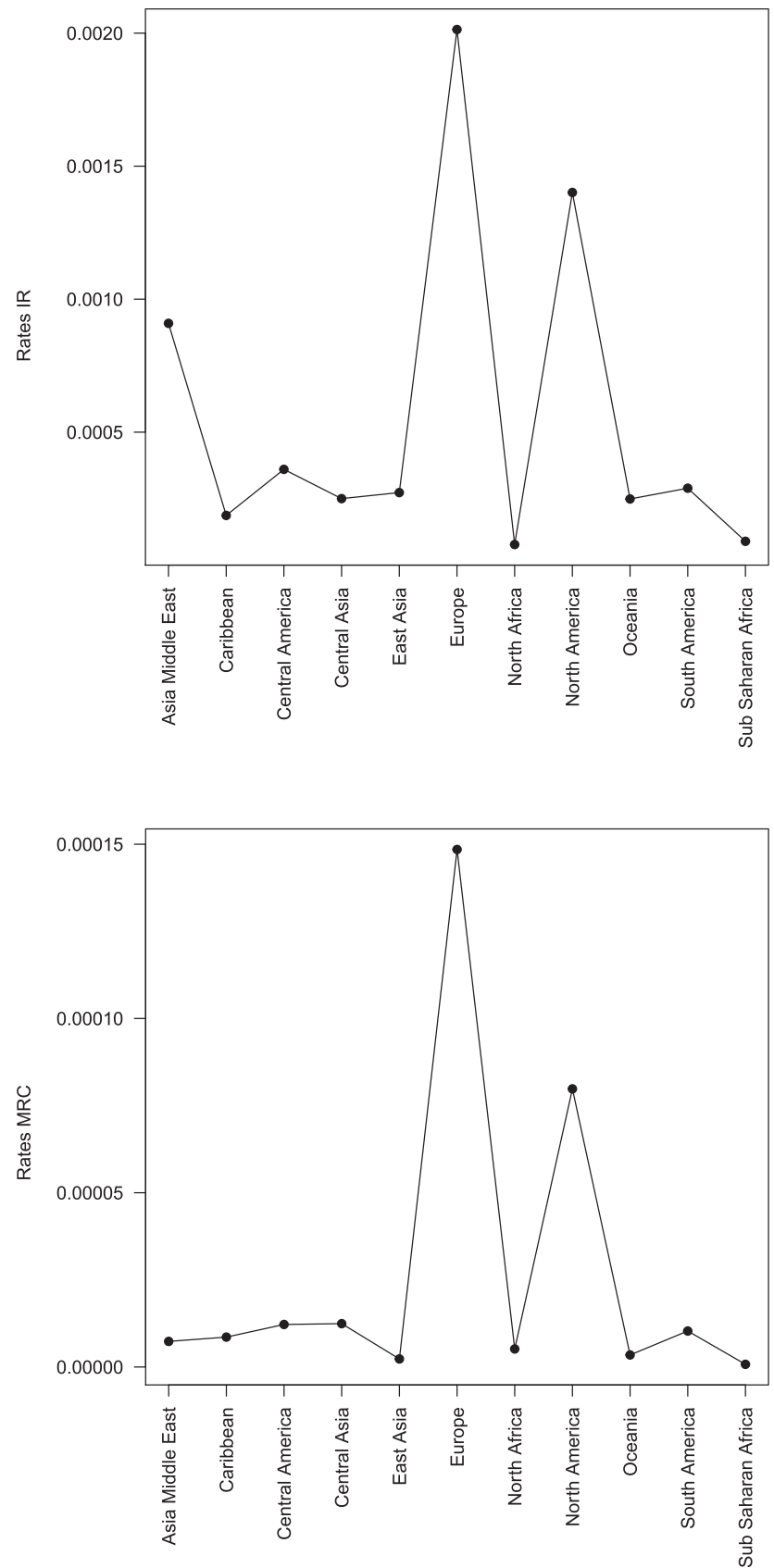

Figure 4: Plots of the means for the IR in different regions of the world (the numbers are based on the cumulative number of cases and deaths).
Figure 5: Plots of the means for the MRC in different regions of the world (the numbers are based on the cumulative number of cases and deaths).

In other direction, since the parameters $\beta_{1}, \beta_{2}, \beta_{4}$ and $\beta_{6}$ are estimated by negative values, it is possible to interpret that when there is increasing of urban population, infant mortality rate, \%GDP spent on health and $\log (\mathrm{GDP})$ per capita there is a decreasing in the IR. The correlation founds in relation to the largest urban population, the highest infant mortality rate, as the lowest IR, needs to be better evaluated, considering that the opposite of this scenario would be expected, since it is known that the disease has spread more easily in urban areas, while so far, there is no association between IR and the infant mortality rate. The other covariates do not show significant effects on the means (95\% credible intervals contain the zero value). Similar interpretations could be given for the parameters associated to the regression model for the precision parameter $\Phi$. The regression parameters associated to the 11 regions of the world do not show significant differences. 


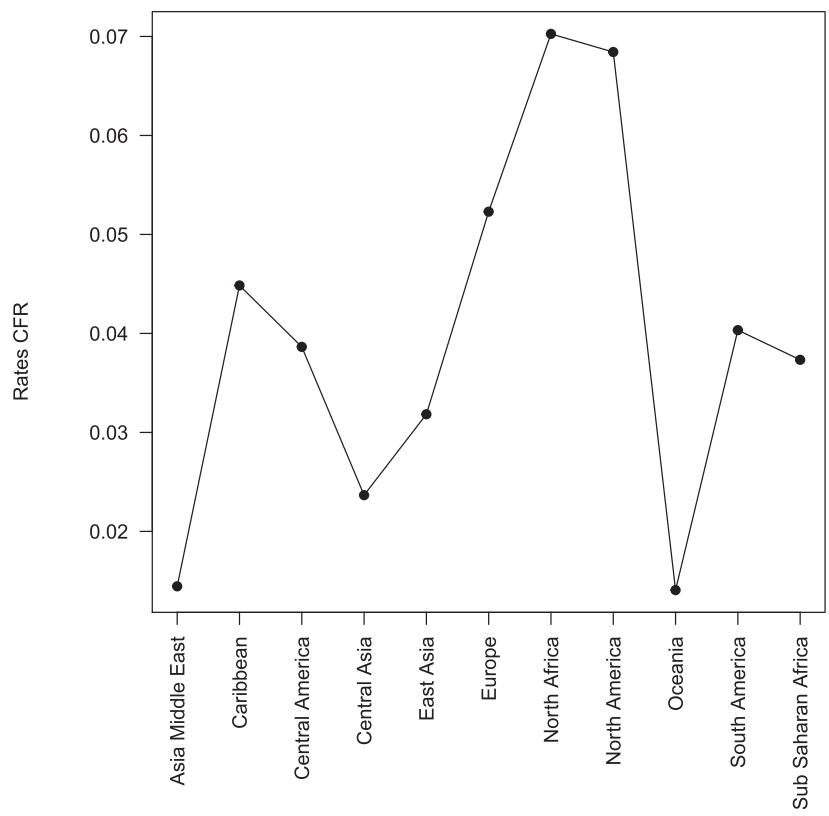

Figure 6: Plots of the means for the CFR in different regions of the world (the numbers are based on the cumulative number of cases and deaths).

\section{Response: $Y_{2}(M R C)$}

Table 3 shows the posterior summaries of interest, from where it is observed that the following covariates show significant effects ( $95 \%$ credible intervals do not contain the zero value for the respective regression parameters) assuming the response MRC:

- Urban population (for both regression models on $\mu$ and on $\Phi$, that is, parameters $\beta_{1}$ and $\alpha_{1}$ ).

- Infant mortality rate (for both regression models on $\mu$ and on $\Phi$, that is, parameters $\beta_{2}$ and $\alpha_{2}$ ).

- Physicians by 1,000 inhabitants (for both regression models on $\mu$ and on $\Phi$, that is, parameters $\beta_{3}$ and $\alpha_{3}$ ).

- $\%$ of GDP spent in health (only for regression model on $\Phi$, that is, parameter $\alpha_{4}$ ).

- $\log$ (GDP-US\$ per capita) (for both regression models on $\mu$ and on $\Phi$, that is, parameters $\beta_{6}$ and $\alpha_{6}$ ).

- $\log (\mathrm{GDP})$ (for both regression models on $\mu$ and on $\Phi$, that is, parameters $\beta_{5}$ and $\alpha_{5}$ ).

- Population density by $\mathrm{km}^{2}$ (for both regression models on $\mu$ and on $\Phi$, that is, parameters $\beta_{7}$ and $\alpha_{7}$ ).

- Dummy covariate Europe (only for regression on $\phi$, that is, parameter $\alpha_{13}$ )

In this case, also it is observed that two of the covariates are linked to the economical situation of each country ( $\log ($ GDP-US\$ per capita) and $\log (\mathrm{GDP})$ ); two covariates are linked to social situation of these countries (urban population and population density by $\mathrm{km}^{2}$ ), three covariates are linked to health structure of each country (infant mortality rate, physicians by 1,000 inhabitants and \% GDP spent on heath) and one dummy covariate associate to region (Europe).

By observing the Monte Carlo estimates based on the simulated Gibbs samples for the posterior means (Table 3) for the regression parameters, it is possible to see the effect of each covariate: negative estimates for the regression parameters $\beta_{1}$ (urban population), $\beta_{2}$ (infant mortality rate), $\beta_{5}(\log (\mathrm{GDP})), \beta_{6}(\log (\mathrm{GDP}$ capita)), $\alpha_{13}$ (Europe), $\alpha_{2}$ (infant mortality rate), $\alpha_{3}$ (physicians by 1000 inhabitants), $\alpha_{5}(\log (\mathrm{GDP})), \alpha_{6}(\log$ (GDP capita)), and $\alpha_{7}$ (pop density $/ \mathrm{km}^{2}$ ); positive estimates for the regression parameters $\beta_{3}$ (physicians by 1000 inhabitants), $\beta_{7}$ (pop. density $/ \mathrm{km}^{2}$ ), $\alpha_{1}$ (urban population) and $\alpha_{4}$ (\% of GDP health).

\section{Response: $Y_{3}$ (CFR)}

Table 4 shows the posterior summaries of interest, from where it is observed that the following covariates show significant effects ( $95 \%$ credible intervals do not contain the zero value for the respective regression parameters) assuming the response CFR: 
Table 2: Posterior summaries for the response IR $(r=1)$ assuming a beta regression model for COVID-19 rates.

\begin{tabular}{|c|c|c|c|c|}
\hline \multirow[t]{2}{*}{ Parameters } & \multirow[t]{2}{*}{ Mean } & \multirow[t]{2}{*}{ Std. Dev. } & \multicolumn{2}{|c|}{ 95\% Cred. Int. } \\
\hline & & & Lower limit & Upper limit \\
\hline$\alpha_{0}$ (Intercept) & -0.01822 & 0.09490 & -0.21220 & 0.16230 \\
\hline$\alpha_{1}$ (Urban population) & -0.02986 & 0.00202 & -0.03300 & -0.02621 \\
\hline$\alpha_{2}$ (Infant mortality rate) & -0.04162 & 0.00322 & -0.04730 & -0.03488 \\
\hline$\alpha_{3}$ (Physicians/1000) & 0.01477 & 0.05884 & -0.10390 & 0.13780 \\
\hline$\alpha_{4}(\%$ GDP on health) & -0.21890 & 0.01457 & -0.24470 & -0.18970 \\
\hline$\alpha_{5}(\log (\mathrm{GDP}))$ & 0.16360 & 0.00887 & 0.14510 & 0.17920 \\
\hline$\alpha_{6}(\log ($ GDP per capita) $)$ & -0.08035 & 0.01179 & -0.09908 & -0.05968 \\
\hline$\alpha_{7}$ (pop.density $/ \mathrm{km}^{2}$ ) & -0.04418 & 0.43000 & -0.04502 & -0.04333 \\
\hline$\alpha_{8}$ (Sub-Saharan Africa) & 0.02034 & 0.10130 & -0.18040 & 0.21610 \\
\hline$\alpha_{9}$ (Central Asia) & -0.25000 & 0.10060 & -0.19860 & 0.19570 \\
\hline$\alpha_{10}($ Asia Middle East) & -0.04493 & 0.09528 & -0.23550 & 0.14270 \\
\hline$\alpha_{11}$ (Central America) & -0.02780 & 0.08610 & -0.19320 & 0.15290 \\
\hline$\alpha_{12}($ Caribbean $)$ & -0.00182 & 0.09977 & -0.19780 & 0.19260 \\
\hline$\alpha_{13}$ (Europe) & 0.05176 & 0.08184 & -0.09335 & 0.21520 \\
\hline$\alpha_{14}$ (North Africa) & -0.00151 & 0.10030 & -0.19540 & 0.19140 \\
\hline$\alpha_{15}$ (North America) & -0.36300 & 0.09998 & -0.20030 & 0.19500 \\
\hline$\alpha_{16}$ (Oceania) & -0.38700 & 0.10010 & -0.19560 & 0.19760 \\
\hline$\alpha_{17}$ (South America) & -0.00103 & 0.09946 & -0.19980 & 0.19380 \\
\hline$\beta_{0}$ (Intercept) & -2.42400 & 1.07400 & -4.34400 & -0.07547 \\
\hline$\beta_{1}$ (Urban population) & -0.20860 & 0.01978 & -0.24800 & -0.17220 \\
\hline$\beta_{2}$ (Infant mortality rate) & -0.11780 & 0.03105 & -0.18700 & -0.06574 \\
\hline$\beta_{3}$ (Physicians/1000) & 0.20540 & 0.46010 & -0.92170 & 0.72920 \\
\hline$\beta_{4}(\% G D P$ on health) & 0.59870 & 0.15060 & 0.38060 & 0.98240 \\
\hline$\beta_{5}(\log (G D P))$ & -1.97200 & 0.08154 & -2.12500 & -1.81900 \\
\hline$\beta_{6}(\log ($ GDP per capita $))$ & -1.62200 & 0.13950 & -1.92200 & -1.41500 \\
\hline$\beta_{7}$ (pop.density $/ \mathrm{km}^{2}$ ) & 0.25510 & 0.01343 & 0.23780 & 0.27550 \\
\hline$\beta_{8}$ (Sub-Saharan Africa) & 0.26700 & 0.95360 & -1.61000 & 2.11200 \\
\hline$\beta_{9}$ (Central Asia) & 0.00394 & 1.00000 & -1.95500 & 1.94600 \\
\hline$\beta_{10}($ Asia Middle East) & 0.56550 & 0.78830 & -0.92600 & 2.10800 \\
\hline$\beta_{11}$ (Central America) & -0.55980 & 0.83730 & -2.17800 & 1.07300 \\
\hline$\beta_{12}($ Caribbean $)$ & $7.94 \mathrm{E}-4$ & 1.01300 & -1.97300 & 1.99000 \\
\hline$\beta_{13}$ (Europe) & -0.57340 & 0.73850 & -2.01200 & 0.85680 \\
\hline$\beta_{14}$ (North Africa) & -0.95800 & 1.00300 & -1.97900 & 1.95500 \\
\hline$\beta_{15}($ North America $)$ & -0.00735 & 1.00100 & -1.98300 & 1.95800 \\
\hline$\beta_{16}$ (Oceania) & -0.01301 & 0.99850 & -1.95700 & 1.96800 \\
\hline$\beta_{17}$ (South America) & 0.00845 & 0.99840 & -1.96200 & 1.94700 \\
\hline
\end{tabular}

- Urban population (only for regression model on $\Phi$, that is, parameter $\alpha_{1}$ ).

- Infant mortality rate (only for regression model on $\mu$, that is, parameter $\beta_{2}$ ).

- $\quad \%$ of GDP spent in health (only for regression model on $\Phi$, that is, parameter $\alpha_{4}$ ).

- $\quad \log$ (GDP-US\$ per capita) (for both regression models on $\mu$ and on $\Phi$, that is, parameters $\beta_{6}$ and $\alpha_{6}$ ).

- $\log (\mathrm{GDP})$ (only for regression model on $\Phi$, that is, parameter $\alpha_{5}$ ).

- Population density by $\mathrm{km}^{2}$ (for both regression models on $\mu$ and on $\Phi$, that is, parameters $\beta_{7}$ and $\alpha_{7}$ ).

In this case, also it is observed that two of the covariates are linked to the economical situation of each country ( $\log ($ GDP-US\$ per capita) and $\log ($ GDP)); two covariates are linked to social situation of these countries (urban population and population density by $\mathrm{km}^{2}$ ), two covariates are linked to health structure of each country (infant mortality rate and \% GDP spent in heath). By observing the Monte Carlo estimates based on the 
Table 3: Posterior summaries for the response MRC $(r=2)$ assuming a beta regression model for COVID-19 rates.

\begin{tabular}{|c|c|c|c|c|}
\hline \multirow[t]{2}{*}{ Parameters } & \multirow[t]{2}{*}{ Mean } & \multirow[t]{2}{*}{ Std. Dev. } & \multicolumn{2}{|c|}{ 95\% Cred. Int. } \\
\hline & & & Lower limit & Upper limit \\
\hline$\alpha_{0}$ (Intercept) & -0.05722 & 0.00991 & -0.07446 & -0.04754 \\
\hline$\alpha_{1}$ (Urban population) & 0.01819 & 0.08650 & 0.01801 & 0.01825 \\
\hline$\alpha_{2}$ (Infant mortality rate) & -0.03296 & 0.00174 & -0.03445 & -0.03025 \\
\hline$\alpha_{3}$ (Physicians/1000) & -0.02184 & 0.89300 & -0.02347 & -0.02041 \\
\hline$\alpha_{4}(\% G D P$ on health $)$ & 0.00175 & 0.27800 & 0.00106 & 0.00216 \\
\hline$\alpha_{5}(\log (G D P))$ & -0.02055 & 0.12600 & -0.02072 & -0.02017 \\
\hline$\alpha_{6}(\log (G D P$ per capita $))$ & -0.01189 & 0.34800 & -0.01257 & -0.01140 \\
\hline$\alpha_{7}$ (pop.density $/ \mathrm{km}^{2}$ ) & -0.13470 & 0.02340 & -0.13480 & -0.13470 \\
\hline$\alpha_{8}$ (Sub-Saharan Africa) & -0.01117 & 0.08511 & -0.18960 & 0.16510 \\
\hline$\alpha_{9}$ (Central Asia) & 0.75600 & 0.10080 & -0.19980 & 0.20060 \\
\hline$\alpha_{10}($ Asia Middle East $)$ & 0.06425 & 0.14560 & -0.17830 & 0.27280 \\
\hline$\alpha_{11}($ Central America $)$ & 0.00150 & 0.10020 & -0.19680 & 0.19840 \\
\hline$\alpha_{12}($ Caribbean $)$ & -0.03279 & 0.08105 & -0.14950 & 0.14850 \\
\hline$\alpha_{13}$ (Europe) & -0.06469 & 0.00396 & -0.06891 & -0.05644 \\
\hline$\alpha_{14}$ (North Africa) & 0.07812 & 0.05067 & -0.00398 & 0.20260 \\
\hline$\alpha_{15}$ (North America) & -0.00183 & 0.10040 & -0.20070 & 0.19340 \\
\hline$\alpha_{16}$ (Oceania) & -0.00130 & 0.09966 & -0.19930 & 0.19240 \\
\hline$\alpha_{17}$ (South America) & 0.00127 & 0.09820 & -0.19240 & 0.18930 \\
\hline$\beta_{0}$ (Intercept) & -1.99600 & 0.87750 & -3.57400 & -0.06685 \\
\hline$\beta_{1}$ (Urban population) & -0.46890 & 0.04046 & -0.53090 & -0.40180 \\
\hline$\beta_{2}$ (Infant mortality rate) & -0.10610 & 0.05338 & -0.21760 & -0.01399 \\
\hline$\beta_{3}$ (Physicians/1000) & 1.18300 & 0.57800 & 0.36690 & 2.33100 \\
\hline$\beta_{4}(\%$ GDP on health) & 0.55330 & 0.56170 & -0.32360 & 1.27200 \\
\hline$\beta_{5}(\log (G D P))$ & -1.48400 & 0.17600 & -1.74200 & -1.04500 \\
\hline$\beta_{6}(\log (G D P$ per capita $))$ & -0.77480 & 0.19270 & -1.24700 & -0.47630 \\
\hline$\beta_{7}$ (pop.density $/ \mathrm{km}^{2}$ ) & 0.42820 & 0.03068 & 0.37110 & 0.47060 \\
\hline$\beta_{8}$ (Sub-Saharan Africa) & -0.28360 & 1.00800 & -2.27200 & 1.72100 \\
\hline$\beta_{9}$ (Central Asia) & -0.06732 & 0.98600 & -1.97500 & 1.92200 \\
\hline$\beta_{10}($ Asia Middle East) & 0.18180 & 1.06900 & -1.92000 & 2.38200 \\
\hline$\beta_{11}$ (Central America) & 0.00871 & 0.98860 & -1.92300 & 1.95500 \\
\hline$\beta_{12}$ (Caribbean) & 0.21730 & 1.03900 & -1.86300 & 2.15800 \\
\hline$\beta_{13}$ (Europe) & -0.10380 & 0.83920 & -1.68300 & 1.53100 \\
\hline$\beta_{14}$ (North Africa) & 0.20600 & 0.93070 & -1.63100 & 2.05800 \\
\hline$\beta_{15}$ (North America) & 0.01071 & 1.00400 & -1.95600 & 1.98400 \\
\hline$\beta_{16}$ (Oceania) & -0.01070 & 0.99630 & -1.95600 & 1.96100 \\
\hline$\beta_{17}$ (South America) & -0.02546 & 1.00200 & -1.92900 & 1.93800 \\
\hline
\end{tabular}

simulated Gibbs samples for the posterior means (Table 4) for the regression parameters it is possible to see the effect of each covariate: negative estimates for the regression parameters $\beta_{2}$ (infant mortality rate), $\beta_{6}(\log (\mathrm{GDP}$ per capita)), $\alpha_{1}$ (urban population), $\alpha_{4}$ (\% GDP spent on health), $\alpha_{5}$ (log(GDP)), $\alpha_{6}(\log ($ GDP per capita)); positive estimates for the regression parameters $\beta_{7}$ (pop. density $/ \mathrm{km}^{2}$ ) and $\alpha_{6}$ (\% of GDP per capita).

From the obtained results of this study, using the proposed beta regression model, it is observed that the covariates affecting IR, MRC and CFR for COVID-19 pandemic based on the data of 119 countries could be summarized by:

- Urban population for both regression models on $\mu$ (mean) and on $\Phi$ (parameter linked to precision) for IR and for MRC, as well as, for CFR for the regression model on $\Phi$.

- Infant mortality rate for both regression models on $\mu$ (mean) and on $\Phi$ (parameter linked to precision) for IR and MRC and for CFR for the regression model on $\mu$ (mean). 
Table 4: Posterior summaries for the response CFR ( $r=3)$ assuming a beta regression model for COVID-19 rates.

\begin{tabular}{|c|c|c|c|c|}
\hline \multirow[t]{2}{*}{ Parameters } & \multirow[t]{2}{*}{ Mean } & \multirow[t]{2}{*}{ Std. Dev. } & \multicolumn{2}{|c|}{ 95\% Cred. Int. } \\
\hline & & & Lower limit & Upper limit \\
\hline$\alpha_{0}$ (Intercept) & -0.01124 & 0.08517 & -0.18840 & 0.11630 \\
\hline$\alpha_{1}$ (Urban population) & -0.03760 & 0.00346 & -0.04221 & -0.03090 \\
\hline$\alpha_{2}$ (Infant mortality rate) & -0.00423 & 0.00289 & -0.00967 & 0.00112 \\
\hline$\alpha_{3}$ (Physicians/1,000) & 0.02822 & 0.04732 & -0.03621 & 0.12470 \\
\hline$\alpha_{4}(\%$ GDP on health) & -0.20010 & 0.01820 & -0.23210 & -0.17130 \\
\hline$\alpha_{5}(\log (\mathrm{GDP}))$ & -0.14700 & 0.01054 & -0.16780 & -0.12830 \\
\hline$\alpha_{6}(\log ($ GDP per capita) $)$ & 0.14120 & 0.03016 & 0.08804 & 0.17610 \\
\hline$\alpha_{7}$ (pop.density $/ \mathrm{km}^{2}$ ) & -0.03791 & 0.20000 & -0.03833 & -0.03759 \\
\hline$\alpha_{8}$ (Sub-Saharan Africa) & 0.91200 & 0.09768 & -0.19540 & 0.19400 \\
\hline$\alpha_{9}$ (Central Asia) & 0.00652 & 0.09339 & -0.18270 & 0.18990 \\
\hline$\alpha_{10}($ Asia Middle East) & 0.03480 & 0.08566 & -0.13290 & 0.20240 \\
\hline$\alpha_{11}$ (Central America) & -0.10230 & 0.08966 & -0.27930 & 0.06621 \\
\hline$\alpha_{12}$ (Caribbean) & 0.08596 & 0.06671 & -0.03393 & 0.22310 \\
\hline$\alpha_{13}$ (Europe) & -0.02402 & 0.09117 & -0.20860 & 0.14900 \\
\hline$\alpha_{14}$ (North Africa) & 0.00265 & 0.10050 & -0.20160 & 0.20060 \\
\hline$\alpha_{15}$ (North America) & -0.00275 & 0.10050 & -0.20400 & 0.19580 \\
\hline$\alpha_{16}$ (Oceania) & -0.63500 & 0.10030 & -0.19570 & 0.19740 \\
\hline$\alpha_{17}$ (South America) & $4.1 \mathrm{E}-01$ & 0.09845 & -0.19910 & 0.19010 \\
\hline$\beta_{0}$ (Intercept) & -2.55700 & 1.01300 & -4.52100 & -0.56300 \\
\hline$\beta_{1}$ (Urban population) & 0.03444 & 0.03757 & -0.02483 & 0.12450 \\
\hline$\beta_{2}$ (Infant mortality rate) & -0.14540 & 0.06126 & -0.25560 & -0.00975 \\
\hline$\beta_{3}$ (Physicians/1000) & 0.08384 & 0.58470 & -1.12700 & 1.15500 \\
\hline$\beta_{4}(\% G D P$ on health) & -0.04063 & 0.23290 & -0.45060 & 0.43480 \\
\hline$\beta_{5}(\log (G D P))$ & -0.13760 & 0.41790 & -0.85350 & 0.53430 \\
\hline$\beta_{6}(\log ($ GDP per capita $))$ & -1.90400 & 0.63330 & -2.69600 & -0.63680 \\
\hline$\beta_{7}$ (pop.density $/ \mathrm{km}^{2}$ ) & 0.09527 & 0.01494 & 0.07096 & 0.12440 \\
\hline$\beta_{8}$ (Sub-Saharan Africa) & -0.03485 & 0.98350 & -2.00600 & 1.85300 \\
\hline$\beta_{9}$ (Central Asia) & 0.04304 & 0.96380 & -1.81800 & 1.98100 \\
\hline$\beta_{10}($ Asia Middle East) & -0.32040 & 0.86750 & -2.01600 & 1.39900 \\
\hline$\beta_{11}$ (Central America) & 0.99750 & 0.90840 & -0.77470 & 2.77100 \\
\hline$\beta_{12}($ Caribbean $)$ & -1.06800 & 0.93810 & -2.91800 & 0.72260 \\
\hline$\beta_{13}$ (Europe) & 0.41120 & 0.87380 & -1.27100 & 2.06300 \\
\hline$\beta_{14}$ (North Africa) & -0.03380 & 0.98310 & -1.98900 & 1.82300 \\
\hline$\beta_{15}($ North America) & 0.00444 & 0.99220 & -1.95000 & 1.98500 \\
\hline$\beta_{16}$ (Oceania) & -0.00749 & 1.00300 & -2.00400 & 1.96700 \\
\hline$\beta_{17}$ (South America) & -0.00591 & 0.99570 & -1.86600 & 1.95300 \\
\hline
\end{tabular}

- $\quad \log$ (GDP-US\$ per capita) for the regression models on $\mu$ (mean) and on $\Phi$ (parameter linked to precision) for the IR, for MRC and for CFR.

- $\log (\mathrm{GDP})$ for the regression models on $\mu$ (mean) and on $\Phi$ (parameter linked to precision) for IR and for MRC and for the CFR only for the regression model on $\Phi$.

- $\%$ GDP spent in health for the regression models on $\mu$ (mean) and on $\Phi$ (parameter linked to precision) for IR and for CFR and CFR only for the regression model on $\Phi$.

- Population density by $\mathrm{km}^{2}$ for the regression models on $\mu$ (mean) and on $\Phi$ (parameter linked to precision) for IR, for MRC and for CFR.

- Physicians by 1,000 inhabitants for the regression models on $\mu$ (mean) and on $\Phi$ (parameter linked to precision) for the MRC.

- Dummy covariate Europe only for regression on $\Phi$ for MRC. 
In summary, from the results of this study some economic indicators (GDP-US\$ per capita, GDP), health indicators (infant mortality rate, \% GDP spent on health, Physicians by 1000 inhabitants), sociodemographic indicators (urban population, Population density by $\mathrm{km}^{2}$ ) and some differences in regions are the most important factors which could impact in better or worse results for the COVID-19 pandemic in different countries of the world. However, all of these results must be considered with great caution, since the pandemic of COVID-19 has been shown to be extremely dynamic, with patterns of distribution, contagion, transmissibility among continents, and even often within the same country, where marked differences have been observed (Nepomuceno et al. 2020; Raciborski et al. 2020). It is important to note that, while writing this manuscript, we observed the interiorization and ruralization of COVID-19 in some countries (Joob and Wiwanitkit 2020; Sriwijitalai and Wiwanitkit 2020), which suggests that we know very little about the properties of SARS-CoV-2 and its interaction/ adaptation with the environment and the human beings K.-H. Chan (2020).

Other important aspects to consider in view of the results we found, as we use three main epidemiological indicators (IR, MRC and CFR) as responses, are the countries' ability to diagnose in a timely manner, as well as to report cases properly and accurately, avoiding underdiagnoses and underreporting of cases and deaths. These points are highly dependent on the massive testing capacity of symptomatic and/or asymptomatic infected people and their contacts, as well as on the structure responsible for the registration of cases and deaths. This is undoubtedly a major limitation of our study, since, when studying data from 119 countries, these points undergo great differences among them, considering the socioeconomic profile and the health infrastructure of each of them.

\section{Concluding remarks}

The main goal of this paper was try to understand the different epidemiological indicators of morbidity (IR) and mortality (MRC and CFR), among the coronavirus novel around the world, using a beta regression model. For that, it has been considered a beta regression structure based on logit and log links assuming a re-parametrized version of beta distribution to describe the respective rates derived from daily reported cases and deaths by COVID-19 until May 04, 2020, for 119 countries. The proposed methodology can be extended by using other factors, such as the daily rate of social isolation. When available, the inclusion of additional covariates may provide more accurate model fits, whose underlying results may offer suggestions on how fast the virus will spread in the short-term period. The proposed regression model has shown to accommodate well the nature of the epidemiological rates by COVID-19. Nevertheless, the present methodology can also be used to provide a comprehensive understanding the dynamics of the epidemic by SARS-CoV-2, which may alert authorities to keep restrictive strategies to control the advance of the pandemic, especially in more impoverished regions and with precarious health systems.

Acknowledgments: The authors thank the editor and reviewers for the important suggestions that led to the great improvement of the manuscript.

Research funding: None declared.

Author contributions: All authors have accepted responsibility for the entire content of this manuscript and approved its submission.

Competing interests: Authors state no conflict of interest. 


\section{Appendix 1}

Table 5: Daily number of cases and deaths in May 04, 2020.

\begin{tabular}{|c|c|c|c|c|}
\hline Country & Cases & Deaths & Population & Region \\
\hline Burkina Faso & 662 & 45 & $19,751,535$ & Sub Saharan Africa \\
\hline Congo & 229 & 10 & $5,244,363$ & Sub Saharan Africa \\
\hline Cote divoire & 1,398 & 17 & $25,069,229$ & Sub Saharan Africa \\
\hline Democratic Republic Congo & 684 & 34 & $84,068,091$ & Sub Saharan Africa \\
\hline Djibouti & 1,112 & 2 & 95,8920 & Sub Saharan Africa \\
\hline Equatorial Guinea & 315 & 1 & $1,308,974$ & Sub Saharan Africa \\
\hline Ethiopia & 135 & 3 & $109,224,559$ & Sub Saharan Africa \\
\hline Gabon & 335 & 5 & $2,119,275$ & Sub Saharan Africa \\
\hline Ghana & 2,169 & 18 & $29,767,108$ & Sub Saharan Africa \\
\hline Guinea & 1,586 & 7 & $12,414,318$ & Sub Saharan Africa \\
\hline Kenya & 465 & 24 & $51,393,010$ & Sub Saharan Africa \\
\hline Mali & 563 & 27 & $19,077,690$ & Sub Saharan Africa \\
\hline Nigeria & 2,558 & 87 & $195,874,740$ & Sub Saharan Africa \\
\hline Senegal & 1,182 & 9 & $15,854,360$ & Sub Saharan Africa \\
\hline South Africa & 6,783 & 131 & $57,779,622$ & Sub Saharan Africa \\
\hline Sudan & 678 & 41 & $41,801,533$ & Sub Saharan Africa \\
\hline United Republic Tanzania & 480 & 16 & $56,318,348$ & Sub Saharan Africa \\
\hline Zambia & 124 & 3 & $17,351,822$ & Sub Saharan Africa \\
\hline Zimbabwe & 34 & 4 & $14,439,018$ & Sub Saharan Africa \\
\hline Afghanistan & 2,704 & 85 & $37,172,386$ & Central Asia \\
\hline Iran & 97,424 & 6203 & $81,800,269$ & Central Asia \\
\hline Kazakhstan & 3,964 & 27 & $18,276,499$ & Central Asia \\
\hline Kyrgyzstan & 830 & 10 & $6,315,800$ & Central Asia \\
\hline Pakistan & 20,186 & 462 & $212,215,030$ & Central Asia \\
\hline Uzbekistan & 2,149 & 10 & $32,955,400$ & Central Asia \\
\hline Bahrain & 3,383 & 8 & $1,569,439$ & Asia Middle East \\
\hline Iraq & 2,296 & 97 & $38,433,600$ & Asia Middle East \\
\hline Israel & 16,208 & 232 & $8,883,800$ & Asia Middle East \\
\hline Jordan & 461 & 9 & $9,956,011$ & Asia Middle East \\
\hline Kuwait & 4,983 & 38 & $4,137,309$ & Asia Middle East \\
\hline Lebanon & 737 & 25 & $6,848,925$ & Asia Middle East \\
\hline Oman & 2,568 & 12 & $4,829,483$ & Asia Middle East \\
\hline Palestine & 522 & 4 & 4569087 & Asia Middle East \\
\hline Qatar & 15,551 & 12 & $2,781,677$ & Asia Middle East \\
\hline Saudi Arabia & 27,011 & 184 & $33,699,947$ & Asia Middle East \\
\hline Turkey & 126,045 & 3,397 & $82,319,724$ & Asia Middle East \\
\hline United Arab Emirates & 14,163 & 126 & $9,630,959$ & Asia Middle East \\
\hline Costa Rica & 739 & 6 & $4,999,441$ & Central America \\
\hline Dominican Republic & 7,954 & 333 & $10,627,165$ & Central America \\
\hline El Salvador & 555 & 12 & $6,420,744$ & Central America \\
\hline Guatemala & 703 & 17 & $17,247,807$ & Central America \\
\hline Honduras & 1,055 & 82 & $9,587,522$ & Central America \\
\hline Panama & 7,197 & 200 & $4,176,873$ & Central America \\
\hline Cuba & 1,649 & 67 & $11,338,138$ & Caribbean \\
\hline Jamaica & 469 & 9 & $2,934,855$ & Caribbean \\
\hline Puerto Rico & 1,808 & 97 & $3,195,153$ & Caribbean \\
\hline Trinidad and Tobago & 116 & 8 & $1,389,858$ & Caribbean \\
\hline Bangladesh & 9,455 & 177 & $161,356,039$ & East Asia \\
\hline China & 83,964 & 4,637 & $1,392,730,000$ & East Asia \\
\hline India & 42,533 & 1,373 & $1,352,617,328$ & East Asia \\
\hline Indonesia & 11,192 & 845 & $267,663,435$ & East Asia \\
\hline
\end{tabular}


Table 5: (continued)

\begin{tabular}{|c|c|c|c|c|}
\hline Country & Cases & Deaths & Population & Region \\
\hline Japan & 15,057 & 510 & $126,529,100$ & East Asia \\
\hline Malaysia & 6,298 & 105 & $31,528,585$ & East Asia \\
\hline Philippines & 9,223 & 607 & $106,651,922$ & East Asia \\
\hline Singapore & 18,205 & 18 & $5,638,676$ & East Asia \\
\hline South Korea & 10,801 & 252 & $51,635,256$ & East Asia \\
\hline Thailand & 2,969 & 54 & $69,428,524$ & East Asia \\
\hline Vietnam & 271 & 0 & $95,540,395$ & East Asia \\
\hline Albania & 795 & 31 & $2,866,376$ & Europe \\
\hline Andorra & 748 & 45 & 77,006 & Europe \\
\hline Armenia & 2,386 & 35 & $2,951,776$ & Europe \\
\hline Austria & 15,597 & 598 & $8,847,037$ & Europe \\
\hline Azerbaijan & 1932 & 25 & 9942334 & Europe \\
\hline Belarus & 16,705 & 99 & $9,485,386$ & Europe \\
\hline Belgium & 49,906 & 7,844 & $11,422,068$ & Europe \\
\hline Bosnia-Herzegovina & 1,857 & 77 & $3,323,929$ & Europe \\
\hline Bulgaria & 1,618 & 73 & $7,024,216$ & Europe \\
\hline Croatia & 2,096 & 79 & $4,089,400$ & Europe \\
\hline Cyprus & 872 & 20 & $1,189,265$ & Europe \\
\hline Czechia & 7,781 & 248 & $10,625,695$ & Europe \\
\hline Denmark & 9,523 & 484 & $5,797,446$ & Europe \\
\hline Estonia & 1,700 & 55 & $1,320,884$ & Europe \\
\hline Finland & 5,254 & 230 & $5,518,050$ & Europe \\
\hline France & 131,287 & 24,895 & $66,987,244$ & Europe \\
\hline Georgia & 589 & 5 & $3,731,000$ & Europe \\
\hline Germany & 163,175 & 6,692 & $82,927,922$ & Europe \\
\hline Greece & 2,626 & 144 & $10,727,668$ & Europe \\
\hline Hungary & 3,035 & 351 & $9,768,785$ & Europe \\
\hline Iceland & 1,799 & 10 & 353,574 & Europe \\
\hline Ireland & 21,506 & 1303 & $4,853,506$ & Europe \\
\hline Italy & 210,717 & 28,884 & $60,431,283$ & Europe \\
\hline Lithuania & 1,410 & 46 & $2,789,533$ & Europe \\
\hline Luxembourg & 3,824 & 96 & 607,728 & Europe \\
\hline Moldova & 4,121 & 125 & $3,545,883$ & Europe \\
\hline Netherlands & 40,571 & 5,056 & $17,231,017$ & Europe \\
\hline North Macedonia & 1,511 & 84 & $2,082,958$ & Europe \\
\hline Norway & 7,809 & 208 & $5,314,336$ & Europe \\
\hline Poland & 13,693 & 678 & $37,978,548$ & Europe \\
\hline Portugal & 25,282 & 1,043 & $10,281,762$ & Europe \\
\hline Romania & 13,163 & 780 & $19,473,936$ & Europe \\
\hline Russia & 134,687 & 1,280 & $144,478,050$ & Europe \\
\hline San Marino & 582 & 41 & 33,785 & Europe \\
\hline Serbia & 9,464 & 193 & $6,982,084$ & Europe \\
\hline Slovakia & 1,408 & 24 & $5,447,011$ & Europe \\
\hline Slovenia & 1,439 & 96 & $2,067,372$ & Europe \\
\hline Spain & 217,466 & 25,264 & $46,723,749$ & Europe \\
\hline Sweden & 22,317 & 2,679 & $10,183,175$ & Europe \\
\hline Switzerland & 29,822 & 1,472 & $8,516,543$ & Europe \\
\hline Ukraine & 11,913 & 288 & $44,622,516$ & Europe \\
\hline United Kingdom & 186,599 & 28,446 & $66,488,991$ & Europe \\
\hline Algeria & 4,474 & 463 & $42,228,429$ & North Africa \\
\hline Egypt & 6,465 & 429 & $98,423,595$ & North Africa \\
\hline Morocco & 4,903 & 174 & $36,029,138$ & North Africa \\
\hline Tunisia & 1,013 & 42 & $11,565,204$ & North Africa \\
\hline Canada & 59,474 & 3682 & $37,058,856$ & North America \\
\hline Mexico & 23,471 & 2,154 & $126,190,788$ & North America \\
\hline
\end{tabular}


Table 5: (continued)

\begin{tabular}{lrrrl}
\hline Country & Cases & Deaths & Population & Region \\
\hline United States of America & $1,158,041$ & 67,682 & $327,167,434$ & North America \\
Australia & 6,801 & 95 & $24,992,369$ & Oceania \\
New Zealand & 1,137 & 20 & $4,885,500$ & Oceania \\
Argentina & 4,770 & 246 & $44,494,502$ & South America \\
Bolivia & 1,594 & 76 & $11,353,142$ & South America \\
Brazil & 101,147 & 7,025 & $209,469,333$ & South America \\
Chile & 19,663 & 260 & $18,729,160$ & South America \\
Colombia & 7,668 & 340 & $49,648,685$ & South America \\
Ecuador & 29,538 & 1,564 & $17,084,357$ & South America \\
Paraguay & 396 & 10 & $6,956,071$ & South America \\
Peru & 45,928 & 1,286 & $31,989,256$ & South America \\
Uruguay & 655 & 17 & $3,449,299$ & South America \\
Venezuela & 357 & 10 & $28,870,195$ & South America \\
\hline
\end{tabular}

\section{References}

Bates, D. M., and D. G. Watts. 1980. "Relative Curvature Measures of Nonlinearity.” Journal of the Royal Statistical Society: Series B (Methodological) 42: 1-16.

Bates, D. M., and D. G. Watts. 1988. Nonlinear Regression Analysis and its Applications, Vol. 2, New York: Wiley.

Bello-Chavolla, O. Y., A. González-Díaz, N. E. Antonio-Villa, C. A. Fermín-Martínez, A. Márquez-Salinas, A. Vargas-Vázquez, J. P. Bahena-López, C. García-Peña, C. A. Aguilar-Salinas, and L. M. Gutiérrez-Robledo. 2020. "Unequal Impact of Structural Health Determinants and Comorbidity on COVID-19 Severity and Lethality in Older Mexican Adults: Looking beyond Chronological Aging." medRxiv 1-25. https://doi.org/10.1093/gerona/glaa163.

Box, G. E., and G. C. Tiao. 2011. Bayesian Inference in Statistical Analysis, Vol. 40, New Jersey, US: John Wiley \& Sons.

Brooks, S. P., and A. Gelman. 1998. "General Methods for Monitoring Convergence of Iterative Simulations." Journal of Computational and Graphical Statistics 7: 434-455.

Cepeda, E., and D. Gamerman. 2005. “Bayesian Methodology for Modeling Parameters in the Two Parameter Exponential Family.” Revista Estadística 57: 93-105.

Cepeda-Cuervo, E., J. A. Achcar, and L. G. Lopera. 2014. "Bivariate Beta Regression Models: Joint Modeling of the Mean, Dispersion and Association Parameters." Journal of Applied Statistics 41: 677-687.

Chan, J. F.-W., S. Yuan, K.-H. Kok, K. K.-W. To, H. Chu, J. Yang, F. Xing, J. Liu, C. C.-Y. Yip, and R. W.-S. Poon. 2020. “A Familial Cluster of Pneumonia Associated with the 2019 Novel Coronavirus Indicating Person-to-Person Transmission: A Study of a Family Cluster." The Lancet 395: 514-523.

Chan, K.-H., S. Sridhar, R. R. Zhang, H. Chu, A. Y.-F. Fung, G. Chan, J. F.-W. Chan, K. K.-W. To, I. F.-N. Hung, V. C.-C. Cheng. 2020. "Factors Affecting Stability and Infectivity of SARS-CoV-2." Journal of Hospital Infection 1-24. https://doi.org/10.1016/j.jhin. 2020.07.009.

Chen, D., W. Xu, Z. Lei, Z. Huang, J. Liu, Z. Gao, and L. Peng. 2020. "Recurrence of Positive SARS-CoV-2 RNA in COVID-19: A Case Report.” International Journal of Infectious Diseases 297-299. https://doi.org/10.1016/j.ijid.2020.03.003.

Chen, J. 2020. "Pathogenicity and Transmissibility of 2019-nCoV: A Quick Overview and Comparison with Other Emerging Viruses." Microbes and Infection 69-71. https://doi.org/10.1016/j.micinf.2020.01.004.

Chen, N., M. Zhou, X. Dong, J. Qu, F. Gong, Y. Han, Y. Qiu, J. Wang, Y. Liu, and Y. Wei. 2020. "Epidemiological and Clinical Characteristics of 99 Cases of 2019 Novel Coronavirus Pneumonia in Wuhan, China: A Descriptive Study.” The Lancet 395: 507-513.

Chen, Y., Q. Liu, and D. Guo. 2020. “Emerging Coronaviruses: Genome Structure, Replication, and Pathogenesis.” Journal of Medical Virology 92: 418-423.

Chennakesavulu, K., and G. R. Reddy. 2020. "The Effect of Latitude and PM2.5 on Spreading of SARS-CoV-2 in Tropical and Temperate Zone Countries." Environmental Pollution 266. 115176. https://doi.org/10.1016/j.envpol.2020.115176.

Chib, S., and E. Greenberg. 1995. "Understanding the Metropolis-Hastings Algorithm." The American Statistician 49: 327-335.

Cousins, S. 2020. "New zealand Eliminates COVID-19." The Lancet 395: 1474.

COVID-19 National Incident Room Surveillance Team and others. 2020. "COVID-19, Australia: Epidemiology Report 18 (Fortnightly Reporting Period Ending 7 June 2020).” Communicable Diseases Intelligence 44: 2018.

da Silva, R. G., M. H. D. M. Ribeiro, V. C. Mariani, and L. S. Coelho. 2020. "Forecasting Brazilian and American COVID-19 Cases Based on Artificial Intelligence Coupled with Climatic Exogenous Variables.” Chaos, Solitons \& Fractals 139: 110027. 
Edson, D. C., D. L. Casey, S. E. Harmer, and F. P. Downes. 2020. "Identification of SARS-CoV-2 in a Proficiency Testing Program." American Journal of Clinical Pathology 1-4. https://doi.org/10.1093/ajcp/aqaa128.

Ferrari, S., and F. Cribari-Neto. 2004. "Beta Regression for Modelling Rates and Proportions." Journal of Applied Statistics 31: 799-815.

Gelfand, A. E., and A. F. Smith. 1990. "Sampling-based Approaches to Calculating Marginal Densities." Journal of the American Statistical Association 85: 398-409.

Gordis, L. 2014. Epidemiology Philadelphia, PA: Elsevier.

Han, Q., Q. Lin, S. Jin, and L. You. 2020. “Coronavirus 2019-nCoV: A Brief Perspective from the Front Line.” Journal of Infection 80: 373-377.

Hazewinkel, M. 2001. Rational Function, Encyclopedia of Mathematics New York: Springer Science Business Media.

Holmes, L., M. Enwere, J. Williams, B. Ogundele, P. Chavan, T. Piccoli, C. Chinacherem, C. Comeaux, L. Pelaez, O. Okundaye. 2020. "Black-white Risk Differentials in COVID-19 (SARS-COV2) Transmission, Mortality and Case Fatality in the United States: Translational Epidemiologic Perspective and Challenges." International Journal of Environmental Research and Public Health 17: 4322.

Huang, C., Y. Wang, X. Li, L. Ren, J. Zhao, Y. Hu, L. Zhang, G. Fan, J. Xu, and X. Gu. 2020. “Clinical Features of Patients Infected with 2019 Novel Coronavirus in Wuhan, China." The Lancet 395: 497-506.

Ilardi, A., S. Chieffi, A. Iavarone. 2020. “SARS-CoV-2 in Italy: Population Density Correlates with Morbidity and Mortality,” Japanese Journal of Infectious Diseases JJID-2020 1-13. https://doi.org/10.7883/yoken.jjid.2020.200.

Joob, B., and V. Wiwanitkit. 2020. "COVID-19 in Rural Non-resort Town: Observation from thailand.” The Australian Journal of Rural Health 28: 184.

Jørgensen, B. 1997. “Proper Dispersion Models.” Brazilian Journal of Probability and Statistics 89-128. https://www.jstor.org/ stable/43600934.

Kandel, N., S. Chungong, A. Omaar, and J. Xing. 2020. "Health Security Capacities in the Context of COVID-19 Outbreak: An Analysis of International Health Regulations Annual Report Data from 182 Countries.” The Lancet 1047-1053. https://doi.org/10.1016/ S0140-6736(20)30553-5.

Lai, C.-C., T.-P. Shih, W.-C. Ko, H.-J. Tang, and P.-R. Hsueh. 2020. "Severe Acute Respiratory Syndrome Coronavirus 2 (SARS-CoV-2) and Corona Virus Disease-2019 (COVID-19): the Epidemic and the Challenges." International Journal of Antimicrobial Agents 105924. https://doi.org/10.1016/j.ijantimicag.2020.105924.

Lan, J., J. Ge, J. Yu, S. Shan, H. Zhou, S. Fan, Q. Zhang, X. Shi, Q. Wang, and L. Zhang. 2020. "Structure of the SARS-CoV-2 Spike Receptor-Binding Domain Bound to the ACE2 Receptor." Nature 581. 215-220.

Lau, H., T. Khosrawipour, P. Kocbach, H. Ichii, J. Bania, and V. Khosrawipour. 2020. "Evaluating the Massive Underreporting and Undertesting of COVID-19 Cases in Multiple Global Epicenters.” Pulmonology 1-6. https://doi.org/10.1016/j.pulmoe.2020. 05.015 .

Li, J.-Y., Z. You, Q. Wang, Z.-J. Zhou, Y. Qiu, R. Luo, and X.-Y. Ge. 2020. “The Epidemic of 2019-Novel-Coronavirus (2019-nCoV) Pneumonia and Insights for Emerging Infectious Diseases in the Future." Microbes and Infection 22: 80-85.

Lu, R., X. Zhao, J. Li, P. Niu, B. Yang, H. Wu, W. Wang, H. Song, B. Huang, and N. Zhu. 2020. "Genomic Characterisation and Epidemiology of 2019 Novel Coronavirus: Implications for Virus Origins and Receptor Binding." The Lancet 395: 565-574.

Lumu, I. 2020. "COVID-19 Response in Sub-saharan Africa: Lessons from Uganda,” Disaster Medicine and Public Health Preparedness 1-5. https://doi.org/10.1017/dmp.2020.248. In press.

Lupia, T., S. Scabini, S. M. Pinna, G. Di Perri, F. G. De Rosa, and S. Corcione. 2020. "2019-novel Coronavirus Outbreak: A New Challenge.” Journal of Global Antimicrobial Resistance 22-27. https://doi.org/10.1016/j.jgar.2020.02.021.

Mendez-Dominguez, N., A. Alvarez-Baeza, and G. Carrillo. 2020. "Demographic and Health Indicators in Correlation to Interstate Variability of Incidence, Confirmation, Hospitalization, and Lethality in Mexico: Preliminary Analysis from Imported and Community Acquired Cases during COVID-19 Outbreak." International Journal of Environmental Research and Public Health 17: 4281.

Miles, A., T. E. Webb, B. Mcloughlin, I. Mannan, A. Rather, P. Knopp, and D. Davis. 2020. “Outcomes from COVID-19 across the Range of Frailty: Excess Mortality in Fitter Older People.” medRxiv 1-11. https://doi.org/10.1007/s41999-020-00354-7.

Nepomuceno, M. R., E. Acosta, D. Alburez-Gutierrez, J. M. Aburto, A. Gagnon, and C. M. Turra. 2020. "Besides Population Age Structure, Health and Other Demographic Factors Can Contribute to Understanding the COVID-19 Burden." Proceedings of the National Academy of Sciences 117: 13881-13883.

Ohia, C., A. S. Bakarey, and T. Ahmad. 2020. “COVID-19 and Nigeria: Putting the Realities in Context.” International Journal of Infectious Diseases 279-281. https://doi.org/10.1016/j.ijid.2020.04.062.

Ongole, J., T. Rossouw, P. B. Fourie, A. Stoltz, J. Hugo, and T. Marcus. 2020. "Sustaining Essential Healthcare in Africa during the COVID-19 Pandemic.” The Union 1-5. https://doi.org/10.5588/ijtld.20. In press.

Osseni, I. A. 2020. "COVID-19 Pandemic in Sub-saharan Africa: Preparedness, Response, and Hidden Potentials." Tropical Medicine and Health 48: 1-3.

Pung, R., C. J. Chiew, B. E. Young, S. Chin, M. I. C. Chen, H. E. Clapham, A. R. Cook, S. Maurer-Stroh, M. P. H. S. Toh, and C. Poh. 2020. "Investigation of Three Clusters of COVID-19 in Singapore: Implications for Surveillance and Response Measures." The Lancet 395: 1039-1046. 
R Core Team. 2019. R: A Language and Environment for Statistical Computing Vienna, Austria: R Foundation for Statistical Computing.

Raciborski, F., J. Pinkas, M. Jankowski, R. Sierpiński, W. S. Zgliczyński, Ł. Szumowski, K. Rakocy, W. Wierzba, and M. Gujski. 2020. "Dynamics of COVID-19 Outbreak in Poland: An Epidemiological Analysis of the First Two Months of the Epidemic," Polish Archives of Internal Medicine 1-20. https://doi.org/10.20452/pamw.15430.

Ribeiro, M. H. D. M., R. G. da Silva, V. C. Mariani, and L. S. Coelho. 2020. "Short-term Forecasting COVID-19 Cumulative Confirmed Cases:," Perspectives for Brazil. Chaos, Solitons \& Fractals 135: 109853.

Ratkowsky, D. 1983. Nonlinear Regression Modelling. New York: Marcel Dekker.

Rocklöv, J., and H. Sjödin. 2020. "High Population Densities Catalyse the Spread of COVID-19." Journal of Travel Medicine 27. 1-2.

Schulz, T., K. Long, K. Kanhutu, I. Bayrak, D. Johnson, and T. Fazio. 2020. "Telehealth during the Coronavirus Disease 2019 Pandemic: Rapid Expansion of Telehealth Outpatient Use during a Pandemic Is Possible if the Programme Is Previously Established." Journal of Telemedicine and Telecare 1-7. https://doi.org/10.1177/1357633X20942045.

Seber, G. A. F., and C. J. Wild. 2003. Nonlinear Regression New Jersey: John Wiley \& Sons.

Shereen, M. A., S. Khan, A. Kazmi, N. Bashir, and R. Siddique. 2020. "COVID-19 Infection: Origin, Transmission, and Characteristics of Human Coronaviruses.” Journal of Advanced Research 91-98. https://doi.org/10.1016/j.jare.2020.03.005.

Sohrabi, C., Z. Alsafi, N. ONeill, M. Khan, A. Kerwan, A. Al-Jabir, C. losifidis, and R. Agha. 2020. "World Health Organization Declares Global Emergency: A Review of the 2019 Novel Coronavirus (COVID-19)." International Journal of Surgery 71-76. https://doi. org/10.1016/j.ijsu.2020.02.034.

Sriwijitalai, W., and V. Wiwanitkit. 2020. “COVID-19 in a Remote Village in a Tropical Forest-A Note." Rural and Remote Health 20: 6014.

Sunjaya, A. F., and A. P. Sunjaya. 2020. “Pooled Testing for Expanding COVID-19 Mass Surveillance.” Disaster Medicine and Public Health Preparedness 1-5. https://doi.org/10.1017/dmp.2020.246. In press.

Varghese, C., and W. Xu. 2020. "Quantifying what Could Have Been-The Impact of the Australian and New Zealand Governments Response to COVID-19," Infection. Disease \& Health 1-3. https://doi.org/10.1016/j.idh.2020.05.003. In press.

World Health Organization. 2016. Ebola Situation Report 30 March 2016 Geneva: World Health Organization.

World Health Organization. 2020a. Coronavirus Disease 2019: Pandemic. Geneva: World Health Organization.

World Health Organization. 2020b. Pandemic, Epidemic Diseases, Disease Outbreaks. Geneva: World Health Organization.

Wu, A., Y. Peng, B. Huang, X. Ding, X. Wang, P. Niu, J. Meng, Z. Zhu, Z. Zhang, and J. Wang. 2020. "Genome Composition and Divergence of the Novel Coronavirus (2019-nCoV) Originating in China." Cell Host \& Microbe 325-328. https://doi.org/10. 1016/j.ijsu.2020.02.034.

Wu, J. T., K. Leung, and G. M. Leung. 2020. "Nowcasting and Forecasting the Potential Domestic and International Spread of the 2019-nCoV Outbreak Originating in Wuhan, China: A Modelling Study." The Lancet 395: 689-697.

Zhao, S., Q. Lin, J. Ran, S. S. Musa, G. Yang, W. Wang, Y. Lou, D. Gao, L. Yang, and D. He. 2020. “Preliminary Estimation of the Basic Reproduction Number of Novel Coronavirus (2019-nCoV) in China, from 2019 to 2020: A Data-Driven Analysis in the Early Phase of the Outbreak." International Journal of Infectious Diseases 92: 214-217. 